\title{
Multiple drug resistance of enteropathogenic Escherichia coli isolated from children with diarrhea in Kashan, Iran
}

\author{
Motallebi Mitra ${ }^{1}$, Piroozmand Ahmad ${ }^{1}$, Rohani Mehdi ${ }^{1}$, Akbari Hosein ${ }^{2}$ and Khorshidi Ahmad ${ }^{1 *}$ \\ ${ }^{1}$ Department of Microbiology and Immunology, Faculty of Medicine, Kashan University of Medical Sciences, \\ Kashan, I. R. Iran. \\ ${ }^{2}$ Department of Biostatistics and Public Health, Faculty of Health, Kashan University of Medical Sciences Kashan, \\ I. R. Iran. \\ Accepted 19 July, 2011
}

\begin{abstract}
Enteropathogenic Escherichia coli (EPEC) is a major cause of diarrhea in infants and children in developing countries. However, recent studies have shown its prevalence in developed countries. The purpose of this study was to evaluate the multi-drug resistant (MDR) of EPEC isolated from children less than five years old with diarrhea hospitalized in Kashan Shahid Beheshti hospital during 2009-10. Stool samples were collected from 313 children less than five years old with diarrhea at Shahid Beheshti Hospital, Kashan, Iran, from November 2009 to May 2010. Specimens were examined by polymerase chain reaction (PCR) test to determine the eae gene for detection of EPEC pathotype. The isolated multi-drug resistance pattern of EPEC was evaluated by disk diffusion agar. The antimicrobial disks used were ampicillin, nalidixic acid, ceftriaxone, ciprofloxacin, cefalexin, ceftazidime, streptomycin and imipenem. Of all $178 \mathrm{E}$. coli cases $51(28.6 \%)$ EPEC pathotypes were isolated. The prevalence of EPEC was higher in children less than one year old. MDR rate in EPEC was $70.6 \%$.The exact application of antibiogram test is necessary before antibiotic prescription for complete treatment and prevention of diarrhea caused by multi-drug resistant agents.
\end{abstract}

Key words: Enteropathogenic Escherichia coli, multiple drugs resistant, children, diarrhea.

\section{INTRODUCTION}

Diarrheal illness is a major public health problem worldwide, with over 2 million deaths occurring each year, particularly among infants younger than 5 years

${ }^{*}$ Corresponding author. E-mail: Khorshidi_A@kaums.ac.ir. Tel: 00983615550021 . Fax: 00983615551112.

Abbreviations: AE, Attaching and effacing; Bfp, bundleforming pilus; EAF, Escherichia coli adherence factor; EPEC, enteropathogenic E. coli; LA, localized adherence; LEE, locus of enterocyte effacement; MDR, multi-drug resistance; PCR, polymerase chain reaction; eae, EPEC attaching and effacing; EMB, eosin methylene blue; TSI, triple sugar iron agar; DNA, deoxyribonucleic acid. (www.who.int). Enteropathogenic Escherichia coli (EPEC), one of the six E. coli diarrheagenic pathotypes, produces an adherence factor chromosomally encoded by the EPEC attaching and effacing (eae) gene located within the locus for enterocyte effacement (LEE) pathogenicity island (Moon et al., 1983; McDaniel and Kaper, 1997; Nataro and Kaper, 1998; Afset et al., 2004). EPEC induces a distinctive histopathology known as the attaching and effacing $(\mathrm{A} / \mathrm{E})$ lesion, which is characterized by the intimate attachment of bacteria to the epithelial surface and effacement of host enterocyte microvilli. There are three stages in EPEC pathogenesis: (i) initial adherence to the host cell, (ii) production and translocation of bacterial proteins through a needle complex via a type III secretory system, and (iii) intimate 
Table 1. PCR primers and conditions for amplification of eae.

\begin{tabular}{ll}
\hline eae & Target \\
\hline CCCGAATTCGGCACAAGCATAAGC & Forward primer \\
CCCGGATCCGTCTCGCCAGTATTCG & Reverse primer \\
$94^{\circ} \mathrm{C}, 2 \mathrm{~min} ; 94^{\circ} \mathrm{C}, 30 \mathrm{~s} ; 52^{\circ} \mathrm{C} / 30,60 \mathrm{~s} ; 72^{\circ} \mathrm{C}, 60 \mathrm{~s} ; 72^{\circ} \mathrm{C}, 5 \mathrm{~min}$ & PCR condition \\
863 & Amplicon(bp) \\
\hline
\end{tabular}

bacterial attachment with pedestal formation (Chen and Frankel, 2005). Diarrheagenic E. coli is the major cause of gastroenteritis in children in the developing world and is associated with high resistance levels to antibiotics (Ochoa et al., 2009).

This organism may spread to infants during delivery or by contaminated hands. Antibiotic treatment of common bacterial infections plays a crucial role in reducing morbidity and mortality of diseases; however, overuse and misuse of antibiotics in the treatment of diarrhea could lead to increased antibiotic resistance (Jafari et al., 2009). Multi-drug resistant EPEC strains are a common phenomenon in recent researches with worldwide extension. The main objective of this study was to analyze the frequency of EPEC as a cause of diarrhea in children less than five years old as well as to study the resistant isolates to eight microbial agents.

\section{MATERIALS AND METHODS}

In this descriptive study 313 fecal specimens were collected using rectal swab method from all children less than 5 years of age with diarrhea hospitalized in Kashan Shahid Beheshti Hospital during 2009-10. The consent form was taken from the children's parent. This study was approved by the research committee of Kashan University of Medical Sciences. All specimens were added to CaryBlair and transported to the laboratory of the Department of Microbiology and Immunology at Kashan University of Medical Sciences. Samples (swabs from Cary-Blair transport media) were cultured for $E$. coli by streaking directly on selective media including Hecton enteric agar and Eosin methylene blue (EMB) agar (Merck, Germany) and incubating for $24 \mathrm{~h}$ at $37^{\circ} \mathrm{C}$. To confirm $E$ coli, specimens from EMB agar were cultured on biochemical media including Triple sugar iron agar (TSI), MR/VP Broth, SIM, Simmons' citrate agar slant, urea broth, Lysine iron agar (Merck, Germany) and incubated for $24 \mathrm{~h}$ at $37^{\circ} \mathrm{C}$. 178 samples were identified as $E$. coli. Specimens were examined by polymerase chain reaction (PCR) test to determine the eae Gene for detection of EPEC pathotype. E coli colonies growing on the primary culture medium were tested by PCR assay for virulence genes. For deoxyribonucleic acid (DNA) extraction, a boiling method for release of DNA from cells was used (Aranda et al., 2004). DNA was extracted from bacteria by resuspending one bacterial colony in 100 $\mu \mathrm{l}$ of deionized water, boiling the suspension for $10 \mathrm{~min}$, and centrifuging it at $14,000 \times \mathrm{g}$ for $5 \mathrm{~min}$. The supernatant was then used as the DNA template for PCR. The optimized protocol was carried out with a $25 \mu \mathrm{l}$ mixture containing $13.5 \mu \mathrm{l}$ deionized water, $2.5 \mu \mathrm{l}$ 10X PCR buffer, $1 \mathrm{mM} \mathrm{MgCl}, 1 \mathrm{mM}$ concentration of each deoxynucleoside triphosphate, $0.5 \mathrm{U}$ of Taq DNA polymerase (Fermentas, Germany) $5 \mu \mathrm{l}$ of the DNA template, and $1 \mu \mathrm{l}$ of primers mix 1 or 2 containing $10 \mathrm{ng}$ primer/ $\mu \mathrm{L}$. The primer sequences and cycling conditions used in the PCR (Thermal cycler,Bioneer South Korea) analysis are listed in Table 1 (Zhang et al., 2002). The PCR product bands were separated by electrophoresis through $1.2 \%$ agarose gel in 1× TBE buffer Figure 1. DNA fragments were visualized by ethidium bromide staining and photographed under ultraviolet light illumination. In all experiments, the DNA mixture from the EPEC strain served as the positive control (EPEC strain was confirmed by pasture institute of Iran). EPEC isolates were tested for susceptibility to ciprofloxacin $(5 \mu \mathrm{g})$, nalidixic acid (30 $\mu \mathrm{g})$, cefalexin $(30 \mu \mathrm{g})$, imipenem $(10 \mu \mathrm{g})$, ceftriaxon $(30 \mu \mathrm{g})$, ceftazidime $(30 \mu \mathrm{g})$, streptomycin $(10 \mu \mathrm{g})$, and ampicillin $(10 \mu \mathrm{g})$ by the Kirby-Bauer disk diffusion method (MAST House, Merseyside, United Kingdom) according to the Clinical Laboratory Standards Institute guideline (CLSI, 2006). Multi-drug resistant isolates were defined as those resistant to three or more classes of antibiotic agents. Antibiotics were classified according to five classes including: 1. Fluoroquinolones (ciprofloxacin, nalidixic acid), 2. Penicillins (ampicillin), 3. Aminoglycosides (streptomycin), 4. Cephalosporins (cefalexin, ceftriaxon, ceftazidime) and 5. Penems (imipenem). All data were entered into SPSS software and comparative statistics were evaluated by chi-square test and Fisher's exact test. $\mathrm{P} \leq 0.05$ was considered to be significant.

\section{RESULTS}

The diarrhea surveillance study for antimicrobial drug susceptibility was conducted from November 2009 to May 2010. The mean \pm SD age of the children studied was $16.6 \pm 12.4$ months. E. coli was isolated from 178 of 313 stool specimens (57.8\%), then 51 (28.6\%) EPEC pathotypes were isolated from $178 \mathrm{E}$. coli cases.

In children with diarrhea 21 were male and 30 were female. The frequency of EPEC was higher in children less than five years old. According to the definition of multi-drug resistance (MDR) by Lockhart et al. (2007). $70.6 \%$ EPEC isolates were multi-drug resistant. The results suggested that there was no correlation between genus and antibiotic-resistant classes (3 or more classes) (P>0.05) (Table 2). The results of MDR based on children age with diarrhea showed that the number of MDR cases was higher present in the group less than one year, but there was no correlation between age and MDR. $(P>0.05)$ (Table 2).

In terms of duration of hospitalization of patients with antibiotic resistance to three and more than three antibiotics, most cases of MDR (17.41\%) was among patients hospitalized for 2-3 days, however there was no statistically significant association between the duration of hospitalization and MDR ( $P>0.05)$ (Table 2).

It should be noted that the highest rates of resistance 


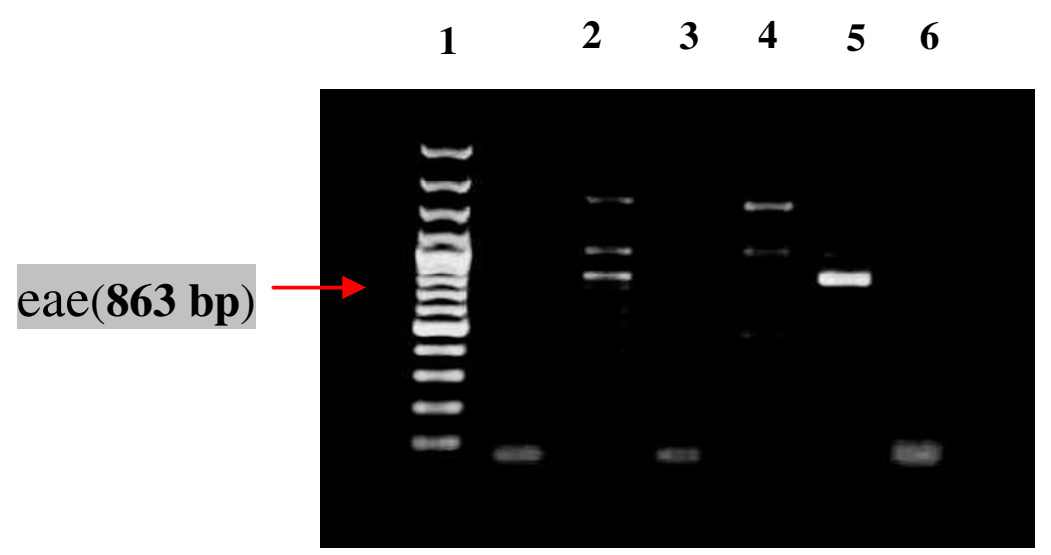

Figure 1. Agarose gel electrophoresis of products from PCR associated gene eae $E$. coli in some diarrhea samples. Left to right, lane 1, DNA molecular size markers (100-bp ladder)(Fermentas); lane 2, patient sample (eae); lane 3, patient sample (Without eae gene ); lane 4, patient sample(Without eae gene); lane 5, EPEC E2348/69 (positive control), lane 6, patient sample (Without eae gene).

Table 2. Antibiotic resistance of 51 EPEC isolated from children less than five years old with diarrhea in Kashan, Iran from 2009 to 2010.

\begin{tabular}{|c|c|c|c|c|c|}
\hline \multirow{2}{*}{ Factor } & & \multicolumn{3}{|c|}{ Antibiotic resistance classes } & \multirow{2}{*}{ P. value } \\
\hline & & $<3$ & $3 \leq$ & Total & \\
\hline \multirow{2}{*}{ Sex } & male & $(33.3) 7$ & $(66.7) 14$ & $(41.18) 21$ & \multirow{2}{*}{0.607} \\
\hline & Female & $(26.7) 8$ & $(73.3) 22)$ & $(58.82) 30$ & \\
\hline \multirow{3}{*}{ Age(year) } & $<1$ & $(29.2) 7$ & $(70.8) 17$ & $(47.06) 24$ & \multirow{3}{*}{0.796} \\
\hline & $1-2$ & $(22.2) 2$ & $(77.8) 7$ & $(17.65) 9$ & \\
\hline & $>2$ & $(33.3) 6$ & $(66.7) 12$ & $(35.29) 18$ & \\
\hline \multirow{3}{*}{ Duration of hospitalization (Day) } & $\leq 1$ & $(14.3) 1$ & $(85.7) 6$ & $(13.73) 7$ & \multirow{3}{*}{0.541} \\
\hline & $2-3$ & $(32.3) 10$ & $(67.7) 21$ & $(60.78) 31$ & \\
\hline & $4-6$ & $(30.8) 4$ & $(69.2) 9$ & $(25.49) 13$ & \\
\hline
\end{tabular}

were to ampicillin (100\%), cephalexin (84\%), and ceftriaxone (74.5\%) (Figure 2).

\section{DISCUSSION}

According to findings, $51(28.6 \%)$ of 178 E. coli were positive for EPEC pathotype. The frequency of EPEC was higher in children less than five years old. The results showed that EPEC was one of the important causes of diarrhea in children younger than five years referred to shahid Beheshti Hospital from November 2009 to May 2010. Cravioto et al. (1996) have reported that the rate of diarrhea caused by EPEC in children less than one year was $51.3 \%$.

Different studies on the prevalence of diarrheal infections in children have showed that this prevalence was a wide range. These values in Southeast Asia studies were of different rates $(2.7 \%)$ than in Singapore $(12.6 \%)$ and Thailand (Sunthadvanich et al., 1990; Lim et al., 1992). Three studies in Brazil have reported that the prevalence of EPEC isolates were from 10.1 to $32.7 \%$ (Rosa et al., 1998; Franzolin et al., 2005) .

Our results showed that the rate of diarrhea caused by EPEC in female and male were $30(58.8 \%)$ and 21 $(41.2 \%)$, respectively. Similarly, in some studies the high prevalence of EPEC was reported in female children along with diarrhea (Afset et al., 2004). Thus, all studies are indicated the role of EPEC as a main factor in the creation of diarrheal infections, especially in children less than five years, but it seems that the prevalence is highly variable. These results need further studies for creating epidemiological map of diarrheal infections caused EPEC. The treatment with antibiotics can lead to shorter 


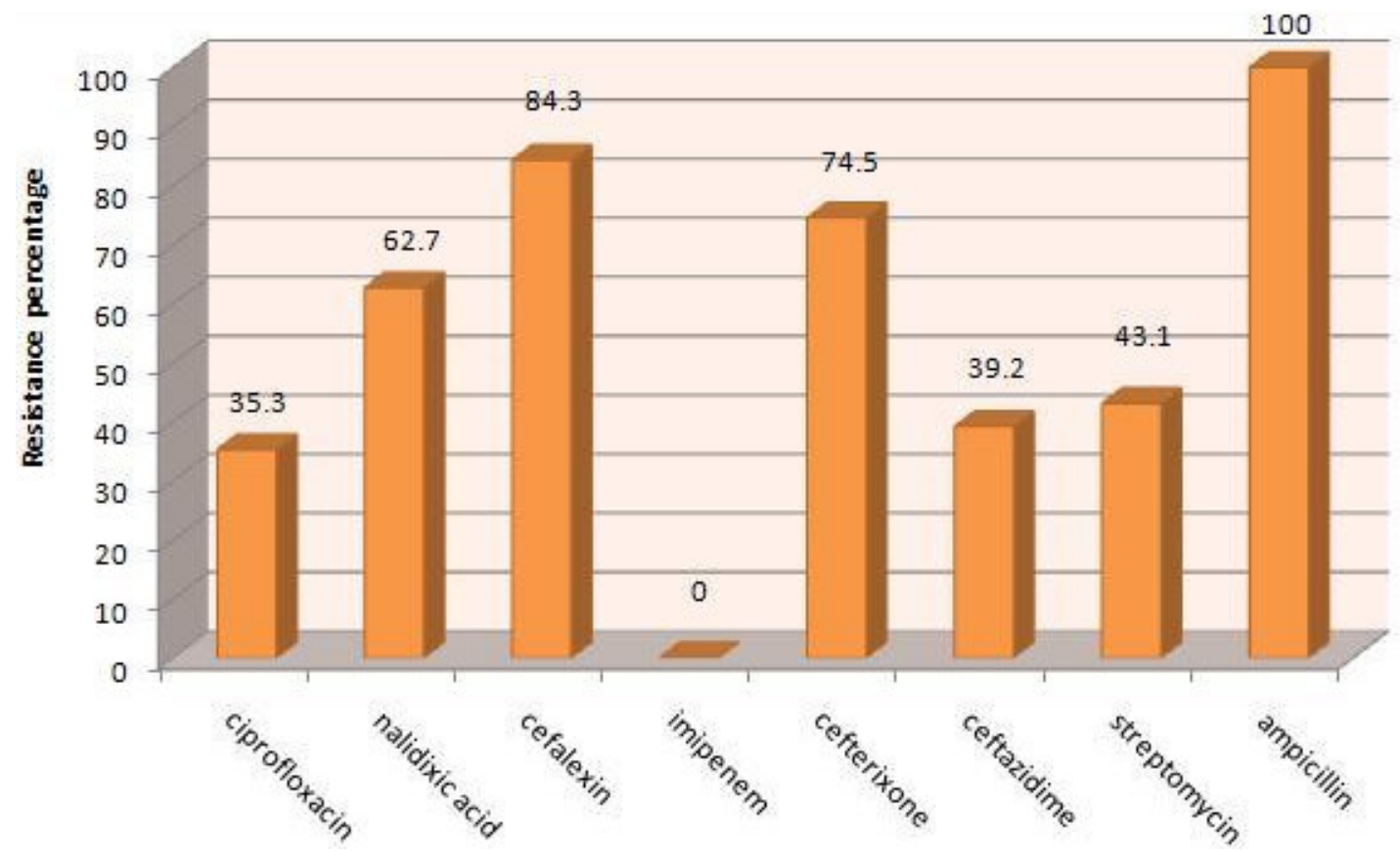

$\square$ Series1

Figure 2. Antibiotic resistance pattern of EPEC isolated from children hospitalized in Kashan Shahid Beheshti Hospital during 2009-2010.

disease period in children with diarrhea. In this study, the MDR rate of EPEC pathotype was evaluated against common antibiotics. Our results showed that MDR rate in EPEC was $70.6 \%$. In a study by Moyenuddin and colleagues in the United States of America showed that about $75 \%$ of these strains were resistant at least to one drug and $64 \%$ to multiple drugs (Moyenuddin et al., 1989). Similarly, a study in Mexico reported that MDR of EPEC pathotype in children less than five years old was $67 \%$ (Estrada-Garcia et al., 2005). However in another study by Nguyen et al. (2005) in Vietnam 2004, on children in this region, MDR rate of pathotype EPEC was $86 \%$. It seems that indiscriminate use of antibiotics without physician prescription in Vietnam was one of the main causes of high levels of MDR. Our results showed that MDR rates were higher in the group of less than one year. Similarly, Ochoa et al. (2009) reported that MDR rate of EPEC Pathotype in children with 2-12 months age was $47 \%$. Most antibiotic resistance was observed to ampicillin, cephalexin, and ceftriaxone (Figure 2).

In a study by Aslani et al. (2008) resistance to streptomycin and ampicillin were reported as 53 and $59 \%$, respectively. Also, none of the samples were resistant to nalidixic acid. While in our study, $62.7 \%$ were resistant to nalidixic acid. This result suggests that resistance to these antibiotics is increasing in recent years.

\section{Conclusion}

These results revealed that EPEC is one of the most important diarrheagenic agents in less than 5 years old children. So diagnostic tests to determine EPEC is necessary in medical laboratories and hospitals at kashan. In other hand according to the variation in antibiotic resistance patterns, diversity in the process and increasing resistance of EPEC pathotype to the antibiotics, these antibiotics should be prescribed with special care.

\section{ACKNOWLEDGMENT}

The authors gratefully thank Kashan University of Medical Sciences for financial support of this research.

\section{REFERENCES}

Afset JE, Bevanger L, Romundstad P, Bergh K (2004). Association of atypical enteropathogenic Escherichia coli (EPEC) with prolonged diarrhoea. J. Med. Microbiol., 53, 1137-1144.

Aranda KR, Fagundes-Neto U, Scaletsky IC (2004). Evaluation of multiplex PCRs for diagnosis of infection with diarrheagenic Escherichia coli and Shigella spp. J. Clin. Microbiol., 42: 5849-5853.

Aslani MM, Ahrabi SS, Alikhani YM, Jafari F, Zali RM, Mani M (2008) Molecular detection and antimicrobial resistance of diarrheagenic Escherichia coli strains isolated from diarrheal cases. Saudi Med. J., 29: 388-392.

Chen HD, Frankel G (2005). Enteropathogenic Escherichia coli: unravelling pathogenesis. FEMS Microbiol. Rev., 29, 83-98.

Cravioto A, Trujillo F, Leon LA, Hernandez JM, Eslava C (1996). [Infections caused by enteropathogenic Escherichia coli]. Gac. Med. Mex., 132, 611-615.

Estrada-Garcia T, Cerna JF, Paheco-Gil L, Velazquez RF, Ochoa TJ,

Torres J, DuPont HL (2005). Drug-resistant diarrheogenic Escherichia coli, Mexico. Emerg. Infect. Dis., 11, 1306-1308. 
Franzolin MR, Alves RC, Keller R, Gomes TA, Beutin L, Barreto ML, Milroy C, Strina A, Ribeiro H, Trabulsi LR (2005). Prevalence of diarrheagenic Escherichia coli in children with diarrhea in Salvador, Bahia, Brazil. Mem. Inst. Oswaldo Cruz, 100: 359-363.

Jafari F, Hamidian M, Rezadehbashi M, Doyle M, Salmanzadeh-Ahrabi S, Derakhshan F, Reza Zali M (2009). Prevalence and antimicrobial resistance of diarrheagenic Escherichia coli and Shigella species associated with acute diarrhea in Tehran, Iran. Can. J. Infect. Dis. Med. Microbiol., 20: e56-62.

Lim YS, Ngan CC, Tay L (1992) Enteropathogenic Escherichia coli as a cause of diarrhoea among children in Singapore. J. Trop. Med. Hyg., 95: 339-342.

Lockhart SR, Abramson MA, Beekmann SE, Gallagher G, Riedel S, Diekema DJ, Quinn JP, Doern GV (2007). Antimicrobial resistance among Gram-negative bacilli causing infections in intensive care unit patients in the United States between 1993 and 2004. J. Clin. Microbiol., 45: 3352-3359.

McDaniel TK, Kaper JB (1997). A cloned pathogenicity island from enteropathogenic Escherichia coli confers the attaching and effacing phenotype on E. coli K-12. Mol. Microbiol., 23: 399-407.

Moon HW, Whipp SC, Argenzio RA, Levine MM, Giannella RA (1983) Attaching and effacing activities of rabbit and human enteropathogenic Escherichia coli in pig and rabbit intestines. Infect. Immun., 41: 1340-1351.

Moyenuddin M, Wachsmuth IK, Moseley SL, Bopp CA, Blake PA (1989). Serotype, antimicrobial resistance, and adherence properties of Escherichia coli strains associated with outbreaks of diarrheal illness in children in the United States. J. Clin. Microbiol., 27: 22342239.
Nataro JP, Kaper JB (1998). Diarrheagenic Escherichia coli. Clin. Microbiol. Rev., 11: 142-201.

Nguyen TV, Le PV, Le CH, Weintraub A (2005). Antibiotic resistance in diarrheagenic Escherichia coli and Shigella strains isolated from children in Hanoi, Vietnam. Antimicrob. Agents Chemother., 49: 816819.

Ochoa TJ, Ruiz J, Molina M, Del Valle LJ, Vargas M, Gil Al, Ecker L, Barletta F, Hall E, Cleary TG, Lanata CF (2009). High frequency of antimicrobial drug resistance of diarrheagenic Escherichia coli in infants in Peru. Am. J. Trop. Med. Hyg., 81: 296-301.

Rosa AC, Mariano AT, Pereira AM, Tibana A, Gomes TA, Andrade JR (1998). Enteropathogenicity markers in Escherichia coli isolated from infants with acute diarrhoea and healthy controls in Rio de Janeiro, Brazil. J. Med. Microbiol., 47: 781-790.

Sunthadvanich R, Chiewsilp D, Seriwatana J, Sakazaki R, Echeverria P (1990). Nationwide surveillance program to identify diarrhea-causing Escherichia coli in children in Thailand. J. Clin. Microbiol., 28: 469472.

Zhang WL, Kohler B, Oswald E, Beutin L, Karch H, Morabito S, Caprioli A, Suerbaum S, Schmidt H (2002). Genetic diversity of intimin genes of attaching and effacing Escherichia coli strains. J. Clin. Microbiol. 40: $4486-4492$ 